MATEC Web of Conferences 10, 04001 (2014)

DOI: $10.1051 /$ matecconf/ 20141004001

(C) Owned by the authors, published by EDP Sciences, 2014

\title{
Investigation of Industrialised Building System Performance in Comparison to Conventional Construction Method
}

\author{
M.A. Othuman Mydin ${ }^{1, \text { a }}$, N. Md Sani ${ }^{2}$, A.F. Phius ${ }^{3}$ \\ ${ }^{1,2,3}$ School of Housing, Building and Planning, Universiti Sains Malaysia, 11800 Penang, Malaysia
}

\begin{abstract}
Conventional construction methods are still widely practised, although many researches have indicated that this method is less effective compared to the IBS construction method. The existence of the IBS has added to the many techniques within the construction industry. This study is aimed at making comparisons between the two construction approaches. Case studies were conducted at four sites in the state of Penang, Malaysia. Two projects were IBS-based while the remaining two deployed the conventional method of construction. Based on an analysis of the results, it can be concluded that the IBS approach has more to offer compared to the conventional method. Among these advantages are shorter construction periods, reduced overall costs, less labour needs, better site conditions and the production of higher quality components.
\end{abstract}

\section{Introduction}

The construction industry in Malaysia is experiencing a migration from conventional methods to a more systematic and mechanised method known as the Industrialised Building System (IBS) [1]. Each state in Malaysia is currently examining the development of the IBS and its potential to overcome the shortage of housing accommodation in this country [2, 3]. The IBS has been acknowledged as being able to offer a potential solution to perk overall performances in the construction sector in terms of increased labour and work quality, reduced costs, sufficient security, waste reductions and enhanced productivities $[4,5]$.

The IBS can be defined as a construction technique where all the components are manufactured in a controlled environment, and are then transported, placed and assembled at the work site with minimal additional structures [6]. The IBS is not only efficient in accelerating the construction of housing projects, but it also improves the quality and affordability of the projects in which the IBS is deployed [7]. Despite the IBS being well-known and accepted by most construction firms due to its theoretical advantages in terms of speed, safety and quality, the wet construction method is still widely regarded in Malaysia as a conventional and safe option despite incurring higher costs and slower completion rates [8]. Conventional construction is one of the earliest approaches practised in the construction industry which does not involve building materials or finished components manufactured by factories.

The conventional method of construction refers to the execution of construction work at the proposed site [9]. It involves the setting up of prefabricated building components at the construction site following the initial installation of a wood or a plywood formwork, reinforcement steel, and cast. Most are built on reinforced concrete frames [10].

\footnotetext{
${ }^{\text {a }}$ Corresponding author: azree@usm.my
} 
However, the authentic conventional construction method uses wooden moulds for this purpose. It has become more expensive due to the rising costs of labour, raw materials, transportation, and also as a result of the long construction periods that are required [11]. Examples of conventional construction, which is also known as cast in-situ, are foundations, frame structures, floors, walls and roofs [12]. It incurs high costs for construction, taking into account the expenditure for labour, raw materials, transportation as well as the required lengthy construction periods [13].

A newly encountered obstacle is the conventional mind-set of buyers, who prefer houses built of brick and mortar [14]. There have been erroneous notions and opinions over one of the pre-cast panels, where buyers think that it is a housing construction element of a lower quality because it is regularly used in the construction of low-cost housing projects in Malaysia [15,16]. Due to the on-going dilemma, developers today are not willing to take the risk of utilizing pre-cast constructions.

The lack of experience and technical knowledge of contractors regarding the IBS have pushed up the costs due to their ineffectiveness in cost management [17]. This situation has given rise to apprehensive feelings with respect to the efficiency of the IBS approach [18]. As local contractors do not possess the appropriate technology and relevant experience pertaining to the management of problems related to quality, productivity as well as safety, they are unable to compete with their counterparts in other countries, who have widely adopted and applied the IBS [19]. Therefore this study was undertaken to identify the strengths and weaknesses of the IBS method and conventional construction methods.

\section{Site Selections}

The case studies in this research were conducted to identify the strengths and weaknesses of the Industrialised Building System as well as those of the conventional method deployed in the construction of 4 targeted projects around Penang. The 4 sites are:

i. The Syariah Court Complex, Penang

ii. The Sekolah Kebangsaan Minden Heights, Gelugor, Penang

iii. The Jamek Mosque, Sg. Gelugor, P

iv. 11 double-storey housing units with basements, George Town, Penang

\section{Case Studies}

These case studies were conducted to identify the strengths and weaknesses of the Industrialised Building System and the conventional method for the four projects around Penang by applying both these methods. The selected projects were the Syariah Court Complex, the Sekolah Kebangsaan Minden Heights, the Jamek Mosque in Sg. Gelugor and also the SP Setia housing project, specifically 11 double-storey housing units with basements. Many researchers have tried to compare these two methods of construction. Through these case studies it has been found that the IBS has significant advantages over the conventional method of construction. Figure 1 shows the erection of a structure at the Sekolah Kebangsaan Minden Heights which was completed within 3 months.

The responses of the relevant people who were interviewed from each of the four projects also pointed in the same direction. For example, in the project involving the construction of Sekolah Kebangsaan Minden Heights, it took less than three months to erect the structure for the building as a whole, while in the case of the Jamek Mosque in Gelugor, a period of four to five months was required to complete the building structure.

This indicates that the IBS approach to construction can cut down on the overall construction period. Statistically, IBS construction projects can save up to $30 \%$ in time compared to conventional methods [12]. 

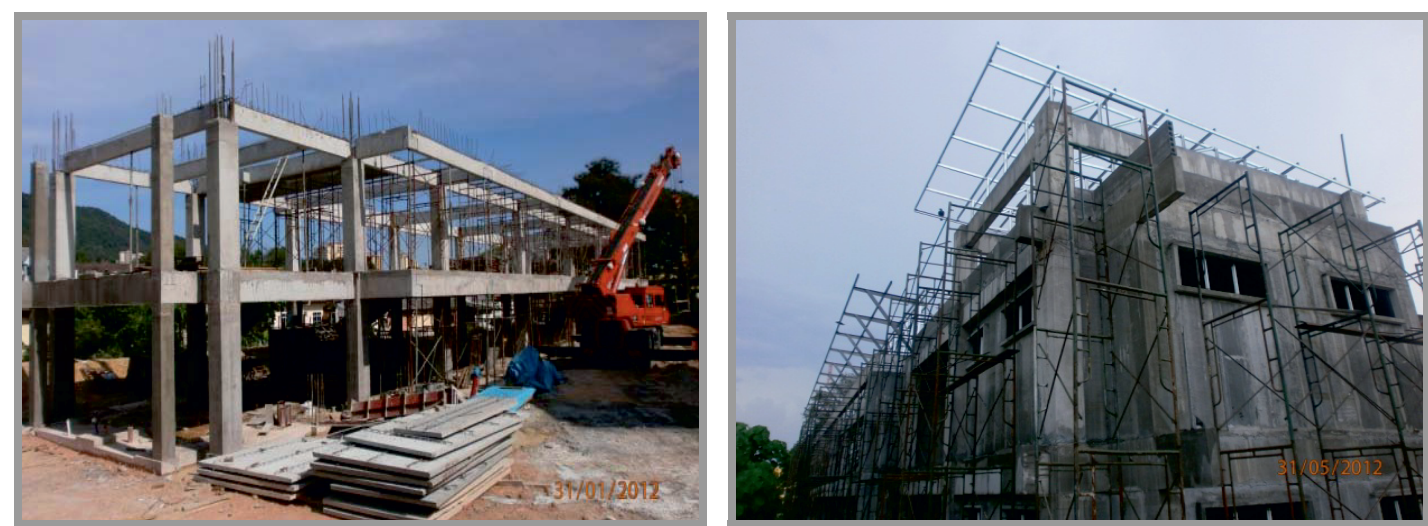

Figure 1. Erection of IBS structural components at Sekolah Kebangsaan Minden Heights

The interviewees also agreed that construction can be completed rapidly because of the earlier manufacturing and assembling of pre-cast components in factories. In contrast, projects that deploy the conventional method are difficult to complete within a short period of time. This method requires a long duration before completion since moulds need to be built and the concrete has to be given enough time to set and so on. Through the case studies of the four construction sites, significant differences in terms of the labour workforce involved could be observed. In fact, one would be able to discern whether a project was deploying the IBS or the conventional approach by casting a single glance at the construction site during working hours.

Construction is a labour-intensive industry, more so in the case of conventional construction methods. However, the IBS application is able to reduce labour at the construction sites. The pre-cast construction method (IBS) is relatively less labour-intensive, but it still requires skilled labour to perform on-site work, such as the installation of the IBS components. This explains the minimal number of labourers because they are only used for the installation of the IBS components [6]. Contrary to conventional methods, which require more labour to complete work such as formwork fabrications, reinforcement bars or steel cage fabrications, formwork installations, reinforcement bar installations, concrete placements and formwork dismantling, the use of the IBS method will reduce the dependency on foreign labour. Figure 2 shows conventional construction methods, which involve more construction workers at the construction site.
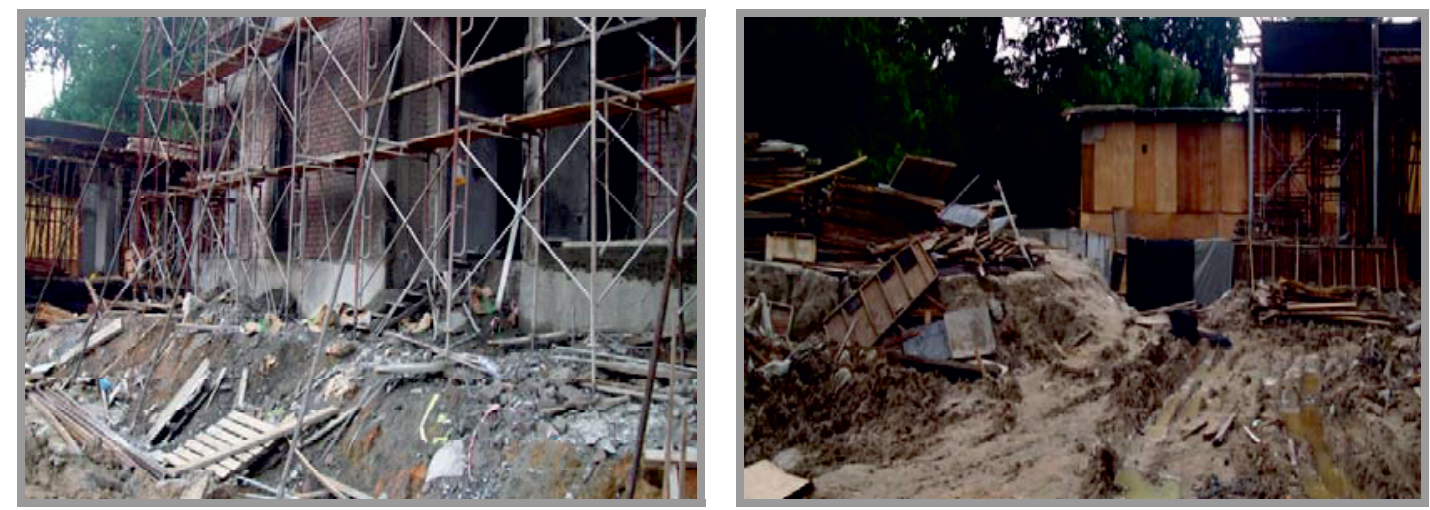

Figure 2. Dirty and untidy construction site

Research has shown that labour efficiency is one of the factors that contribute to increased productivity. It is an important element in projects that will contribute to increased building costs. Decline in labour productivity can reduce wages as a worker is paid according to the amount of work that he does. Workers who do not work optimally at the construction site will impede the progress of 
the project and lengthen its completion. This phenomenon makes the conventional method appear cheaper compared to the IBS approach.

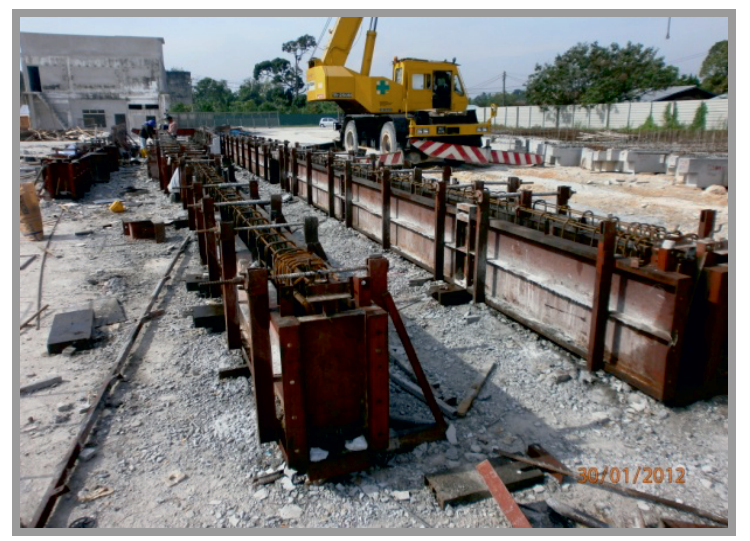

Figure 3. The use of steel formwork for repeated construction

Besides, the IBS incurs lower costs for building large and repetitive designs within a short period of time. This leads to the lowering of the overall cost of the project, provided that the project is a large one which involves a high degree of repetition. However, the costs of the initial stages of construction are usually higher because during these phases the involvement of complex machineries is vital for the preparation, casting, curing and treatment, stripping and de-moulding as well as the inspection, lifting and handling processes. Besides, IBS components are also considered to be costly due to the small number of manufacturers of IBS components in Malaysia. Figure 3 shows the use of steel formworks for a repetitive building to minimize costs and wastage at the construction site.

The IBS requires less labour during construction. Besides, it is also able to eliminate the use of conventional formworks which encourage wastage and excessive costs in construction. This helps to reduce overall costs in the construction of IBS projects as compared to projects using the conventional method, which usually incur high costs, which are partially due to concrete wastage. Figure 4 illustrates the conventional construction using wooden formworks. The construction process will take a long time to complete and is a waste of construction materials.

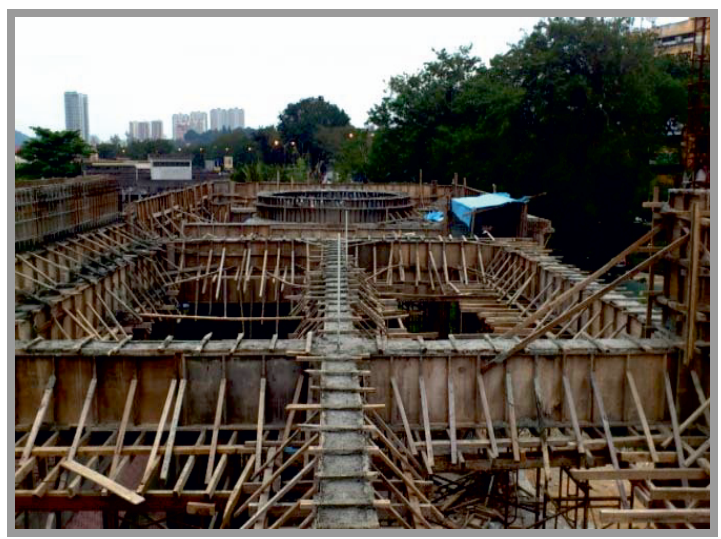

Figure 4. The use of wooden formworks for conventional construction at the Jamek Mosque site

Through the case studies of the four construction projects which were based either on the IBS or the conventional method, it can be concluded that these two construction methods are affected by the way the construction sites are managed by the contractors and the labourers. The IBS method offers economical designs with a guarantee of high quality because it is well managed and regulated. 
Moreover, the IBS building designs are still capable of providing a certain degree of flexibility in their construction to produce a variety of forms, quality and also attractive finishes.

Besides, if there are any changes in terms of the design, the alterations can be done with ease. The usage of the IBS would certainly result in outcomes of good quality because the components are manufactured in well-controlled conditions to obtain high-quality components. Consistency is an important element in the manufacture of these components and extra emphasis is placed on ensuring that each component is produced in accordance with design specifications. The IBS components typically have smooth surfaces as compared to those of the conventional method because the former is made of materials which are superior in quality using advanced technologies and produced under the supervision of prominent experts in the field.

The IBS is able to maintain good site conditions besides being able to create avenues for cleaner and well-organised sites. The IBS sites typically generate minimal construction wastage, save for the required site tools. This is in high contrast to the environmental conditions at construction sites where the conventional method is applied. The conditions at these project sites are messy and disorganised. These do not only pose threats to the safety of the workers but also disrupt their movements in and around the construction sites.

\section{Conclusions}

This study, which is aimed at comparing the IBS construction method to the conventional construction method, was conducted around the state of Penang, Malaysia. The existence of the IBS adds to the many techniques within the construction industry. Based on all the methods that have been implemented through the case studies at the construction sites and through the interview sessions, it can be concluded that the two methods have their own pros and cons as follows:

1. The IBS requires a short period for completion and this is especially the case for the erection of structures.

2. The IBS offers good quality components with better surface finishes, which are more refined than those made possible by the conventional method.

4. The quality of the buildings that are constructed using the conventional method depends very much on the technical knowledge of the labourers as well as their conduct at the construction sites.

5. Leakage sometimes occurs at the connection between two components. This problem may be due to an error in the installation of the components or probably because of an error which occurred during the manufacturing stage.

6. The IBS involves high cost during the initial stages of construction because it requires the involvement of heavy machineries during the manufacturing, delivery and the erection of components at the project sites during construction.

7. The IBS components are considered to be expensive due to the lack of IBS components manufacturers in Malaysia. However, the IBS offers a lower cost of construction in the long run since the cost of labour at the construction site is reduced, wastage is kept to a minimum and the use of moulds is reduced.

8. It is less costly to use the IBS to build large and repetitive designs within a short time. Labourers are often paid their wages according to their performance at the construction sites.

9. The IBS and the conventional method showed significant differences in terms of the cost of labour engaged in both construction systems.

10. The IBS provides a cleaner and well-organised site with minimal construction wastage. It is in contrast to the environment observed at construction sites where the conventional method is being applied. 


\section{References}

1. M.R. Abdul Kadir, W.P. Lee, M.S. Jaafar, S.M. Sapuan and A.A.A. Ali, Factors Affecting Construction Labour Productivity for Malaysian Residential Projects, Journal of Structural Survey. 23 (1) (2005) 42-54

2. W.A.M, Thanoon, L.W. Peng, M.R. Abdul Kadir, M.S. Jaafar, M.S Salit, The Experiences of Malaysia and Other Countries in Industrialized Building System in Malaysia, Proceeding on IBS Seminar. UPM, Malaysia, 2003.

3. R. Abdul Rashid, A Model for an Effective Implementation of the Government Technology Transfer Policy in the Malaysian Construction Industry. Unpublished PhD Thesis. The University of Reading, 1998, 52-80

4. P.C. Bruechle, Steel and Precast Concrete, the Way Forward, Master Builders Journal, 2004.

5. K.S. Elliot, Off Site Prefabrication of Concrete Structures, Proceedings of the International Conference on Industrialised Building Systems IBS 2003, Kuala Lumpur, 2003.

6. L. Flynn, Framing the moment, Building Design and Construction, 2001.

7. K.S. Elliot, Mixed options for Precast Concrete Construction, Building Design and Construction, 2003.

8. Allmon, C.T. Haas, J.D. Borcherding and P.M. Goodrum. U.S Construction Labour Productivity Trends, 1970-1998, Journal of Construction Engineering and Management, 26 (2) (2000) 97-104

9. Aramvareekul. An Analysis of Labor Productivity in the U.S Construction Industry. Unpublished PhD Thesis. The State University of New York at Buffalo, 2002, 76-95.

10. Y.F. Badir, M.R. Abdul Kadir, A.H. Hashim, Industrialized Building Systems Construction in Malaysia , Journal of Architectural Engineering, 8 (1) (2002) 19-23

11. H. Nurul Azam, A.R. Hamzah, H. Mahanim, A Literature Review of the Advantages and Barriers to the Implementation of Industrialied Building System (IBS) in Construction Industry. Malaysian Construction Research Journal, 4 (1) (2009) 10-14.

12. E.M. Rojas, P. Aramvareekul, Labor Productivity Drivers and Opportunities in the Construction Industry, Journal of Management in Engineering, 2 (1) (2003) 78-82

13. H.R. Thomas, A.S. Sakarcan, Forecasting Labor Productivity Using Factor Model, Journal of Construction Engineering and Management, 120 (1) (1994) 228-239

14. C.H. Oglesby, H.W. Parker, G.A. Howell, Productivity Improvement in Construction, McGrawHill Inc., Unites State of America, 1989, 5-9

15. P.F. Kaming, P.O. Olomolaiye, G.D. Holt, F.C. Harris, Factors Influencing Craftsmen's Productivity in Indonesia, International Journal of Project Management, 15 (1) (1997) 21-30

16. P.F. Kaming, G.D. Holt, S.T. Kometa and P.O. Olomolaiye. Severity Diagnosis of Productivity Problems - A Reliability Analysis. International Journal of Project Management. 16(2): 107-113 (1998).

17. A. Kazaz, S. Ulubeyli, A Different Approach to Construction Labour in Turkey: Comparative Productivity Analysis, Journal of Building and Environment, 39 (2004) 93-100.

18. E.C. Lim, J. Alum, Construction Productivity: Issues Encountered by Contractors in Singapore, International Journal of Project Management, 13 (1) (1995) 52-58

19. H. Mc David, Construction and Economic Development a Stimulus or Constraint in Developing Countries, Unpublished PhD Thesis, George Washington University, 1995, 45-88. 